\title{
ADVANCED DIRECT LIQUEFACTION CONCEPTS for PETC GENERIC UNITS \\ Phase II
}

Quarterly Technical Progress Report

for Period April through June 2000

by

University of Kentucky

Center for Applied Energy Research

CONSOL Inc.

Hydrocarbon Technologies, Inc.

LDP Associates

July 2000

Prepared for

The U. S. Department of Energy

Under Contract No.

DE-AC22-91PC91040--88 


\section{Disclaimer}

This report was prepared as an account of work sponsored by an agency of the United States Government. Neither the United States Government nor any agency thereof, nor any of their employees, makes any warranty, express or implied, or assumes any legal liability or responsibility for the accuracy, completeness, or usefulness of any information, apparatus, product, or process disclosed, or represents that its use would not infringe privately owned rights. Reference herein to any specific commercial product, process, or service by trade name, trademark, manufacturer, or otherwise does not necessarily constitute or imply its endorsement, recommendation, or favoring by the United States Government or any agency thereof. The views and opinions of authors expressed herein do not necessarily state or reflect those of the United States Government or any agency thereof. 


\begin{abstract}
The results of Laboratory and Bench-Scale experiments and supporting technical and economic assessments conducted under DOE Contract No. DE-AC22-91PC91040 are reported for the period January 1, 1999 to March 31, 2000. This contract is with the University of Kentucky Research Foundation, which supports work with the University of Kentucky Center for Applied Energy Research, CONSOL, Inc., LDP Associates, and Hydrocarbon Technologies, Inc. This work involves the introduction into the basic two-stage liquefaction process several novel concepts, which include dispersed lower-cost catalysts, coal cleaning by oil agglomeration, and distillate hydrotreating and dewaxing. This project has been modified to include an investigation into the production of value added materials from coal using low-severity liquefaction based technologies.
\end{abstract}




\section{TABLE OF CONTENTS}

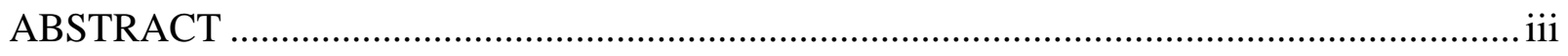

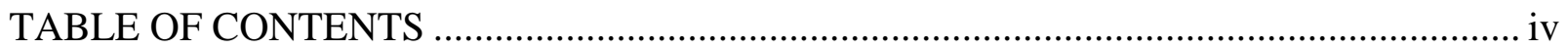

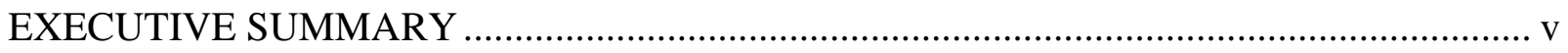

TASK 2. LABORATORY SUPPORT (UK/CAER) ………………………………….....

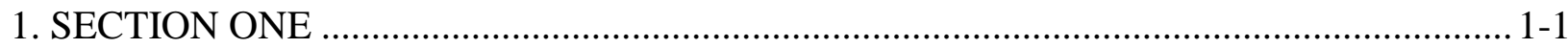

Task 2. LABORATORY SUPPORT (UK/CAER) …………....................................... 1-2

Distillation of Pitch Extraction Mixtures - Continued from DOE/PC/91040-128 ................ 1-2

Analysis of Distillation Condensates. ......................................................................... 1-3

Pitch Extraction Mass Balance Analysis........................................................................ 1-5

Modified Reactor Experiments ................................................................................. 1-6

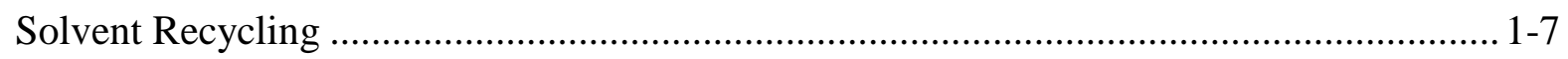

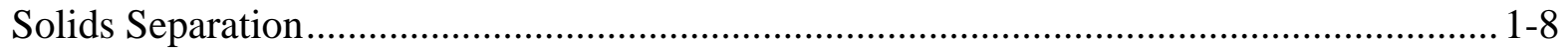

Evaluation of materials produced from co-pyrolysis of coal and MSW by HTI ................ 1-12

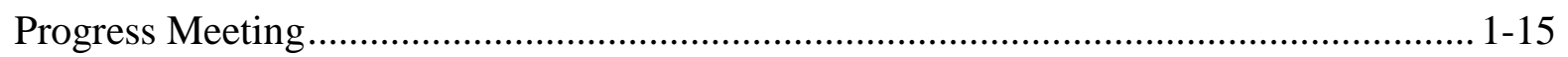

2. SECTION TWO

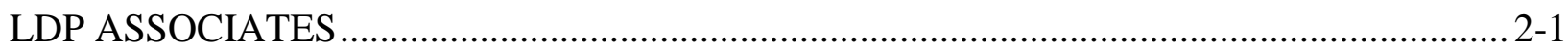

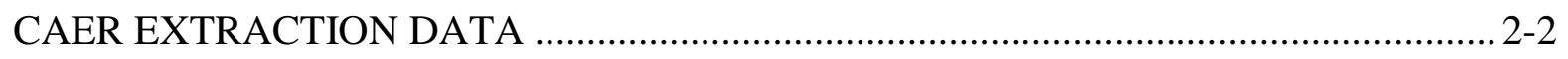

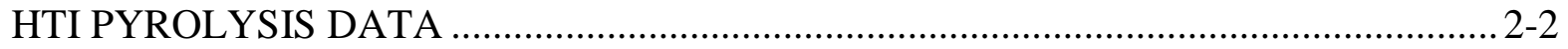

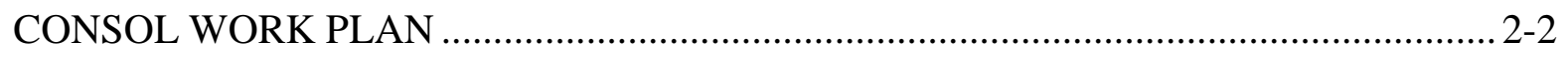

IDENTIFICATION OF TARGETED PRODUCTS ..................................................... 2-2

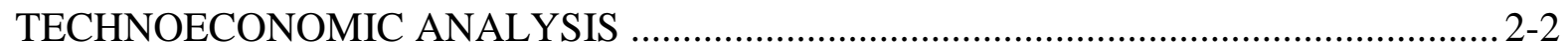

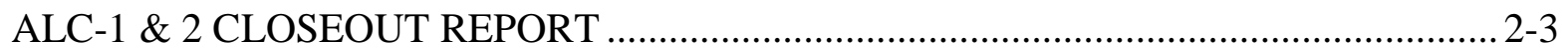

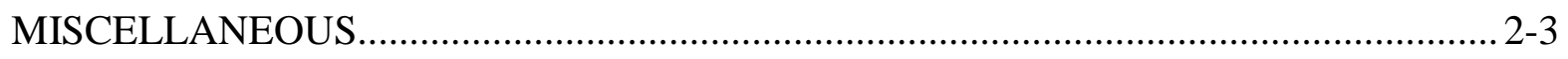

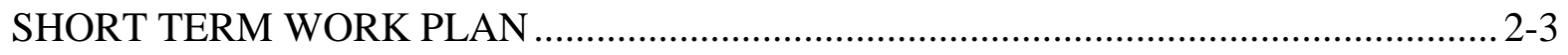




\section{EXECUTIVE SUMMARY}

\section{TASK 2. LABORATORY SUPPORT (UK/CAER)}

Proximate and ultimate analyses of pitches from a previous distillation profile series were completed this quarter. Analytical results from CONSOL on distillation condensates produced at CAER are also reported. The results were not as expected with the phenolic content of condensates similar to fresh anthracene oil. Possible reasons and solutions discussed include: loss of material in reactor lines or the extraction temperature.

Mass balance data are presented for selected pitch extractions performed to date. Although in most cases these data are acceptable some improvements have been pursued. Modifications to tubing bomb reactor configurations are discussed and extractions using the modified reactors were performed. The modifications improved mass balance data, with the balances closing on average at about $95 \%$.

Solvent recycling studies commenced this quarter, with the first of five recycling experiments completed. Results to date do not show significant decreases in pitch yield or coal conversion for solvent extractions after one solvent recycle. These experiments will continue through the next quarter, with sub-samples of distillation condensates forwarded to CONSOL.

Some preliminary work on hot filtering for removal of solids from extraction mixtures was performed. Results from some qualitative work show that extraction mixtures with coal to solvent ratios of 1:2 require temperatures of at least $320{ }^{\circ} \mathrm{C}$ and over-pressure of about 100 psi for any filtration to occur. Filtration of extraction mixtures with coal to solvent ratios of $1: 3$ and 1:4 were more successful, however the economics of using lower coal to solvent ratios would be poor. Alternatives for improving the filterability not involving coal to solvent ratio changes are discussed and will be pursued.

The results and liquid products from HTI's co-pyrolysis of coal and MSW were received this quarter. The data show that mass balance continues to be a problem, which results in very small (almost unusable) quantities of liquids from each experiment. This part of the program will be continued at CAER by CAER since HTI has exhausted their budget for this activity.

Finally, a progress meeting was held on 10 May 2000 at HTI. The major outcomes and discussions have been summarized. 


\section{SECTION ONE}

UNIVERSITY OF KENTUCKY

CENTER FOR APPLIED ENERGY RESEARCH 
TASK 2. LABORATORY SUPPORT (UK/CAER)

\section{Distillation of Pitch Extraction Mixtures - Continued from DOE/PC/91040-128}

As reported previously [Quarterly Technical Progress Report for period January through March 2000 DOE/PC/91040-125] a series of distillations were performed on a Western Kentucky pitch extraction mixture. The final pot temperatures were, $300,310,320,330,340$ and $360{ }^{\circ} \mathrm{C}$ at $1 \mathrm{~mm}$ $\mathrm{Hg}$, final vapor temperature was approximately $305^{\circ} \mathrm{C}$. Although the effect of final pot temperature on softening point was discussed in the above report, no analytical results on the pitches were available. Due to instrumentation problems proximate and ultimate analyses were delayed. Proximate and ultimate analysis data can now be reported, and are summarized in Tables 1 and 2 .

Table 1 - Proximate analysis results for distillation of pitch extraction mixtures.

\begin{tabular}{|c|c|c|c|c|}
\hline Sample \# - Pot Temperature & $\begin{array}{c}\text { Moisture } \\
(\boldsymbol{\%})\end{array}$ & $\begin{array}{c}\text { Ash } \\
(\boldsymbol{\%})\end{array}$ & $\begin{array}{c}\text { Volatiles } \\
(\boldsymbol{\%})\end{array}$ & $\begin{array}{c}\text { Fixed Carbon } \\
(\boldsymbol{\%})\end{array}$ \\
\hline $011300-300$ & 0.03 & 0.08 & 69.50 & 30.39 \\
\hline $011300-310$ & 0.01 & 0.10 & 73.35 & 26.53 \\
\hline $011300-320$ & 0.06 & 0.09 & 59.34 & 40.50 \\
\hline $011300-330$ & 0.09 & 0.08 & 65.47 & 34.37 \\
\hline $011300-340$ & 0.01 & 0.18 & 58.00 & 41.81 \\
\hline $011300-360$ & 0.12 & 0.07 & 55.57 & 44.24 \\
\hline
\end{tabular}

Table 2 - Ultimate analysis for pitches distilled from 300 to $360{ }^{\circ} \mathrm{C}$.

\begin{tabular}{|c|c|c|c|c|c|}
\hline Sample \# - Pot Temperature & $\begin{array}{c}\mathbf{C} \\
(\boldsymbol{\%})\end{array}$ & $\begin{array}{c}\mathbf{H} \\
(\boldsymbol{\%})\end{array}$ & $\begin{array}{c}\mathbf{N} \\
(\boldsymbol{\%})\end{array}$ & $\begin{array}{c}\text { Total S } \\
(\boldsymbol{\%})\end{array}$ & $\mathbf{H} / \mathbf{C}$ \\
\hline $011300-300$ & 87.17 & 5.38 & 1.57 & 1.39 & 0.74 \\
\hline $011300-310$ & 86.46 & 5.38 & 1.57 & 1.41 & 0.75 \\
\hline $011300-320$ & 85.49 & 5.35 & 1.62 & 1.63 & 0.75 \\
\hline $011300-330$ & 85.54 & 5.37 & 1.59 & 1.56 & 0.75 \\
\hline $011300-340$ & 86.02 & 5.51 & 1.63 & 1.63 & 0.77 \\
\hline $011300-360$ & 86.19 & 5.32 & 1.63 & 1.57 & 0.74 \\
\hline
\end{tabular}

Inspection of the data shows that the moisture content of the all pitches is very low, generally less than $0.1 \%$. The results also show very low ash contents in the pitches, again generally less than $0.1 \%$. The low ash results show that there is virtually no carry over of mineral matter from 
the coal into the pitch during the extraction process. This is an important property of pitches used in the fabrication of carbon fibers, since the presence of mineral inclusions can lead to severe problems of fiber spinning and also introduce defects into the structure of the product carbon fibers, with a consequent loss in tensile strength.

Not surprisingly, the percent volatile content of the pitches decreases progressively with increasing final pot temperature, as more volatile components are lost at higher distillation temperatures. The fixed carbon content shows a corresponding increase with decreasing volatiles. Ultimate analysis results show that percent $\mathrm{C}, \mathrm{H}$ and $\mathrm{N}$ are similar for each pitch. $\mathrm{H} / \mathrm{C}$ ratios are also similar.

\section{Analysis of Distillation Condensates.}

Four distillation condensates as well as three samples of anthracene oil were sent to CONSOL Inc for analysis. The condensates are materials recovered from vacuum distillation of pitch extraction mixtures to a final pot temperature of $350{ }^{\circ} \mathrm{C}$ at $1 \mathrm{~mm}$ of $\mathrm{Hg}$. As part of the program, these materials will be assessed for their potential use in producing specialty chemicals. In the first instance the phenolic content was examined since it was thought that phenolic groups may be cleaved from coal during the extraction process.

Table 3 shows a summary of analysis for four condensate samples. Also included are results for two batches of anthracene oil, as well as the condensate from anthracene oil distilled to $350{ }^{\circ} \mathrm{C}$ at $1 \mathrm{~mm} \mathrm{Hg}$. Inspection of Table 2 shows that the phenolic content of the "raw" anthracene oil and the processed condensates are similar. This was not the expected result. There may be several reasons for this. First, the extraction temperature of $350{ }^{\circ} \mathrm{C}$ may be too low to cause satisfactory degradation of the coal. Second, materials may have been lost in the reactor lines of the tubing bomb. Some slightly higher temperature extractions are planned. Furthermore, recent modifications to the tubing bomb reactor (described below) may also address this problem. 
Table 3 - Summary of condensate analyses, ex CONSOL Inc

\begin{tabular}{|c|c|c|c|c|c|c|c|c|c|}
\hline Experiment No. & $\begin{array}{c}\text { 1:2 Extraction } \\
\text { @ } 350^{\circ} \mathrm{C} \text { for } \\
60 \mathrm{~min} .\end{array}$ & $\begin{array}{c}\text { Condensed } \\
\text { Aromatics } \\
(\%)\end{array}$ & $\begin{array}{c}\text { Uncondensed } \\
\text { Aromatics } \\
(\%)\end{array}$ & $\begin{array}{c}\text { Cyclic } \\
\text { Alpha } \\
(\%)\end{array}$ & $\begin{array}{c}\text { Alkyl } \\
\text { Alpha } \\
(\%)\end{array}$ & $\begin{array}{c}\text { Cyclic Beta } \\
(\%)\end{array}$ & $\begin{array}{c}\text { Alkyl } \\
\text { Beta } \\
(\%)\end{array}$ & $\begin{array}{c}\text { Gamma } \\
(\%)\end{array}$ & $\begin{array}{c}\text {-OH Phenolic } \\
\text { (meq/g) }\end{array}$ \\
\hline A-020700-1 & W.Ky / A.Oil & 65.8 & 11.0 & 5.8 & 6.3 & 7.8 & 1.9 & 1.4 & 0.49 \\
\hline A2-030100-1 & W.Ky / A.Oil & 59.5 & 7.9 & 14.7 & 5.9 & 8.9 & 2.0 & 1.2 & 0.46 \\
\hline A-020700-1 & B.T / A.Oil & 60.2 & 8.6 & 13.6 & 5.1 & 8.6 & 2.3 & 1.5 & 0.41 \\
\hline \multicolumn{2}{|c|}{ Condensate Composite Sample } & 72.1 & 10.9 & 6.8 & 6.0 & 1.8 & 1.2 & 1.2 & 0.46 \\
\hline \multicolumn{2}{|c|}{ Anthracene Oil - Batch 1} & 68.6 & 12.6 & 8.1 & 6.3 & 1.9 & 1.3 & 1.2 & 0.42 \\
\hline \multicolumn{2}{|c|}{ Anthracene Oil - Batch 2} & 71.1 & 9.7 & 8.3 & 5.8 & 3.0 & 1.1 & 1.1 & 0.46 \\
\hline
\end{tabular}




\section{Pitch Extraction Mass Balance Analysis}

Whilst the previous quarterly report focussed on fiber fabrication and characterization, this quarter we report on collation and analysis of pitch extraction mass balance data. Table 4 shows mass balance data for a selection of pitch extractions performed to date. The data presented as pitch yield are the \% mass of pitch recovered (DAF) from the extraction that are within the useful softening point temperature range $\left(220-260{ }^{\circ} \mathrm{C}\right)$ for fiber fabrication. The data for coal conversion is the difference between the mass of feed coal and the mass of residual coal recovered after extraction.

Mass balances have been calculated and expressed in two ways. The first is simply based on the ratio of material in versus the mass of material recovered after the extraction. The second balance is expressed in terms of the mass of feed coal.

The mass balances attained are reasonable, ranging from $75 \%$ to just over $100 \%$. The average mass balance for the 15 extractions closes 92\%. The evolved gases associated with the extractions have not been included in the mass balance. Although the volume of gas remaining after extraction was measured, its mass contribution is not significant.

Table 4 - Pitch extraction mass balance summary.

\begin{tabular}{|c|c|c|c|c|c|c|}
\hline Coal & $\begin{array}{c}\text { Pitch Yield } \\
\text { DAF } \\
(\boldsymbol{\%})\end{array}$ & $\begin{array}{c}\text { Coal Conv } \\
\text { DAF } \\
(\boldsymbol{\%})\end{array}$ & $\begin{array}{c}\text { Total } \\
\text { IN }\end{array}$ & $\begin{array}{c}\text { Total } \\
\text { OUT }\end{array}$ & $\begin{array}{c}\text { Bal'ce } \\
\text { Total IN }\end{array}$ & $\begin{array}{c}\text { Bal'ce } \\
\text { Coal } \\
\text { IN }\end{array}$ \\
\hline W.Ky 1 & 58.4 & 45.2 & 300.0 & 272.0 & 90.7 & 72.0 \\
\hline W.Ky 2 & 33.0 & 30.3 & 300.0 & $\mathrm{n} / \mathrm{d}$ & $\mathrm{n} / \mathrm{d}$ & $\mathrm{n} / \mathrm{d}$ \\
\hline W.Ky 3 & 50.9 & 37.5 & 300.0 & 257.8 & 85.9 & 57.8 \\
\hline W.Ky 4 & 68.6 & 51.7 & 300.0 & 303.1 & 101.0 & 103.1 \\
\hline W.Ky 5 & 88.7 & 68.9 & 300.0 & 304.8 & 101.6 & 104.8 \\
\hline W.Ky 6 & 54.8 & 50.8 & 300.0 & 294.9 & 98.3 & 94.9 \\
\hline W.Ky 7 & 65.0 & 48.3 & 300.0 & 290.1 & 96.7 & 90.1 \\
\hline W.Ky 8 & 51.1 & 44.4 & 300.0 & 283.2 & 94.4 & 83.2 \\
\hline Pitt. 1 & 37.5 & 25.0 & 300.0 & 254.5 & 84.8 & 54.5 \\
\hline Pitt 2 & 40.4 & 30.3 & 300.0 & 254.7 & 84.9 & 54.8 \\
\hline Pitt. 3 & 57.4 & 41.3 & 300.0 & 307.1 & 102.4 & 107.1 \\
\hline B.T 1 & 34.7 & 31.0 & 21.0 & 16.1 & 76.7 & 30.0 \\
\hline B.T 2 & 37.9 & 45.9 & 300.0 & 307.3 & 102.4 & 107.3 \\
\hline B.T 3 & 44.4 & 50.1 & 300.0 & 228.4 & 76.1 & 28.4 \\
\hline
\end{tabular}


Although the mass balances shown above are acceptable they can be improved. Balances above $100 \%$, were attributed to residual THF in the distilled condensates. Future extractions will measure the total volume of THF used for washing, soxhleting and rinsing and the volume of THF recovered from rotary evaporating and distillation. For balances below $100 \%$, several sources of material loss have been identified.

There is a very small amount of material lost in the vacuum lines and cold traps during distillation. This material is difficult and tedious to recover, particularly material lost in the vacuum lines. Given that it is only a very small amount no attempt has been made to recover this material.

The largest source of material loss occurs in the tubing bomb reactor lines. There are significant amounts of condensed liquids that become trapped during extraction and are lost later when the bomb is vented to measure off gas volume. To overcome this problem some modifications to the tubing bomb reactor were made.

Face sealing fittings were installed, these fittings allowed easier dismantling of all reactor lines for solvent washing after extraction. A heated line to a cold trap was also added. This modification allowed any volatilized material to be trapped during the extraction, therefore minimizing liquids trapped in lines. Again this line and trap would be solvent rinsed after extraction. Some extractions were preformed using the modified reactor and these are discussed below.

\section{Modified Reactor Experiments}

Western Kentucky coal and anthracene oil was slurried in a ratio of 1:2 respectively and heated to $350{ }^{\circ} \mathrm{C}$ for 60 minutes in the modified tubing bomb reactor. Pitch was recovered from the extraction mixture using the methods described previously [Quarterly Technical Progress Report DOE/PC/91040-120]. Pitch yield, conversion and mass balances calculated are presented below.

Table 5 - Pitch extractions performed with modified tube reactors.

\begin{tabular}{|c|c|c|c|c|}
\hline Experiment No. & $\begin{array}{c}\text { Pitch Yield } \\
(\boldsymbol{\%} \text { daf coal) }\end{array}$ & $\begin{array}{c}\text { Coal Conversion } \\
(\boldsymbol{\%} \text { daf coal })\end{array}$ & $\begin{array}{c}\text { Condensates } \\
\text { Recovered } \\
(\boldsymbol{\%})\end{array}$ & Mass Balance \\
\hline A-051900-1 & 59.9 & 49.8 & 90.4 & 94.6 \\
\hline A-052300-1 & 56.4 & 38.6 & 90.3 & 96.4 \\
\hline
\end{tabular}

Inspection of the data above shows a marked improvement in mass balance. It was also noted that the maximum pressure attained (approximately $53 \mathrm{psi}$ ) during extraction was lower than previous extractions. This was probably a result of the introduction of the cold trap that lowered the vapor pressure inside the reactor. The pitch yields are apparently unaffected by the lower extraction pressures. Samples of condensates from these runs will be forwarded to CONSOL 
Inc, for evaluation. As well, extraction mass balance data has been forwarded to LDP Associates.

\section{Solvent Recycling}

The ability to re-use recovered solvents is an important factor if solvent extraction is to be a viable method in an industrial scale plant. Ideally solvents could be re-used indefinitely if recovered from the extraction process in a sufficiently pure and non-degraded state. However, it is more likely that a small amount of fresh solvent will need to be added during recycling in a continuous or semi-continuous process to replace solvent consumed in the extraction and to maintain solvent inventory. Nevertheless it is important to determine the effect of solvent recycling on pitch yield and coal conversion.

Work has begun on a series of extractions where the anthracene oil condensates recovered from vacuum distillation will be used a solvent for further pitch extractions on fresh coal. Five consecutive cycles will be attempted to determine the effects upon the performance of the recycle solvent. A sub-sample of condensates recovered after each cycle will be taken and forwarded to CONSOL, Inc for evaluation.

In this reporting period, two series of extractions were performed using the modified tubing bomb reactor. Western Kentucky coal and solvent were slurried in ratios of 1:2 (coal:solvent) and heated at $350{ }^{\circ} \mathrm{C}$ for 60 minutes. After the bomb was allowed to cool, the volume of gas produced during the extraction was measured. The extraction results for the initial and $2^{\text {nd }}$ cycle are summarized in Table 6.

The condensates from experiments, A-051900-1 and A-052300-1 were combined and used for the $2^{\text {nd }}$ recycle experiment.

Table 6 - Pitch extraction summary for recycling experiments on Western Kentucky coal.

\begin{tabular}{|c|c|c|c|c|c|c|}
\hline Experiment No. & $\begin{array}{c}\text { Recycle } \\
\text { Number }\end{array}$ & $\begin{array}{c}\text { Pitch Yield } \\
(\boldsymbol{\%} \text { daf coal) }\end{array}$ & $\begin{array}{c}\text { Coal Conversion } \\
(\boldsymbol{\%} \text { daf coal })\end{array}$ & $\begin{array}{c}\text { Condensates } \\
\text { Recovered } \\
(\boldsymbol{\%})\end{array}$ & $\begin{array}{c}\text { Mass } \\
\text { Balance } \\
(\boldsymbol{\%})\end{array}$ & $\begin{array}{c}\text { Pitch } \\
\text { Soft. Pt. } \\
(\mathbf{~} \mathbf{C})\end{array}$ \\
\hline $\begin{array}{c}\text { A- 051900-1+ } \\
\text { A-052300-1 }\end{array}$ & 1 & $\begin{array}{c}58.13 \\
(\text { mean })\end{array}$ & $\begin{array}{c}44.19 \\
(\text { mean })\end{array}$ & $\begin{array}{c}90.37 \\
(\text { mean })\end{array}$ & $\begin{array}{c}95.51 \\
(\text { mean })\end{array}$ & 300 \\
\hline A-060800-1R1 & 2 & 65.03 & 44.44 & 84.55 & 93.30 & 235 \\
\hline
\end{tabular}

The $2^{\text {nd }}$ cycle extraction did not show a decrease in either coal conversion or pitch yield. On the contrary, pitch yield was actually higher for the $2^{\text {nd }}$ cycle run compared to the initial extraction. However the reason for the higher pitch yield was due to a lower amount of condensates recovered from the pitch extraction mixture. That is, more reacted/unreacted solvent was left behind in the pitch; this is further reflected by a lower softening point. 


\section{Solids Separation}

In an industrial scale process the primary function of a solids separation stage is to ensure that particulate solids are not present in the subsequent process streams where they may inhibit process performance or contaminate products. The particular method selected whether based upon filtration, gravity settling, centrifugation or solvent extraction can also have a significant impact upon the economics of the process. Thus, the selection of the method used for solids separation can have a major bearing upon the viability of the process. In the current laboratory scale pitch extractions, separation of residual solids is performed during Soxhlet extraction. The contents of the tube reactor are washed with THF into a Soxhlet extraction thimble contained in a Soxhlet extraction apparatus. During the process of Soxhlet extraction, THF soluble soluble materials are washed away from the residual coal.

Although solvent extraction methods for solids removal have been shown to be effective, it is prudent to consider other methods that may be suited to scale-up and offer economic advantages. On a commercial scale, hot filtration of the reactor products through either a metal screen or series of screens could be used. Hence some preliminary work was initiated this month to investigate the filtration properties of reaction products generated in the current study.

A $35 \mathrm{~mm}$ diameter filter unit was used for these preliminary studies. The filter consisted of a body $225 \mathrm{~mm}$ in length, a flange at one end housed a $47 \mathrm{~mm}$ diameter filter screen and support grid. Filter elements were GFA type glass fiber filters supported on a perforated stainless steel screen with $0.5 \mathrm{~mm}$ diameter holes. A Teflon o-ring served both as a main gasket and to seal the filter element into the filter body. The flange was secured with 3 bolts and wing nuts. The top of the unit was closed with a flanged lid containing a pressure relief valve, thermocouple, 3-way valve and pressure gauge. The top was secured to the filter body with another Teflon o-ring and clamp. The assembled filter body was heated using a vertical tube furnace, the furnace was controlled manually using a variable transformer.

This preliminary study was purely qualitative and did not involve the collection or calculation of filtration rates or cake resistivity. Later work will attempt to determine these parameters. The aim of this work was to assess the viability of using filtration for solids separation with these materials.

Samples were heated in a beaker on a hot plate until the sample was sufficiently fluid such that it could be poured into the filter apparatus. The filter body was filled approximately $1 / 2$ full and the lid closed. The internal temperature of the filter body was monitored and furnace adjusted accordingly. Filtration was attempted at a number of temperatures ranging from 200 to $350{ }^{\circ} \mathrm{C}$, with nitrogen over-pressures ranging from 10 to 100 psi.

The initial trials were performed using the extraction products from the dissolution of a Western Kentucky coal in anthracene oil at a coal to solvent ratio of $1: 2$ heated to $350{ }^{\circ} \mathrm{C}$ for 60 minutes. Inspection of Table 7 shows that no filtration was achieved below $320^{\circ} \mathrm{C}$ and 30 psi overpressure. Furthermore, the rate of filtrate from the filter body was extremely slow with only a few drops of filtrate produced after 15 minutes. 
There are several possible reasons for the poor filtration properties of this extraction mixture, but essentially these reduce to two controlling parameters that are functions of the feed material. Namely, the nature and size distribution of the unreacted solids and secondly, the viscosity of the fluid phase at the operating temperature The other factors that influence filtration rate including filter area, membrane resistance, differential pressure applied across the unit and the concentration of solids in the feed, are more easily controlled. In contrast, where the extraction conditions are too mild, the formation of coal particles that are still soft and plastic may result. Deformation of these particles within the filter cake can result in the formation of cakes with very low permeability and can eventually lead to filter blinding. Similarly, if a high concentration of sub-micron particles derived from the inherent ash and partially dissolved coal macerals are formed, again an impervious filter cake may be produced. It is also possible that the 1:2 coal and anthracene oil reactor products are too viscous to filter successfully.

As a first step to investigate the causes for the low filtration rates, extraction mixtures with different coal to solvent ratios were produced. Mixtures with coal to solvent ratios of, 1:3 and 1:4 were heated to $350{ }^{\circ} \mathrm{C}$ for 60 minutes and these extracts then filtered using the methods described above. Results for filtering experiments are shown below in Table 8.

The results above show that reasonable filtration was achieved for the 1:3 extraction mixture and rapid filtration was achieved for the 1:4 extraction mixture. However these results involve the use of 1.5 to 2 times the amount of solvent compared to the 1:2 extraction mixture which could impact upon the economics of the process. In view of the results above, more work on extraction mixture filterability will continue in the next quarter 
Table 7 - Qualitative filtration results for Western Kentucky coal and anthracene oil extraction mixture heated to $350{ }^{\circ} \mathrm{C}$ for 60 minutes.

\begin{tabular}{|c|c|c|c|c|}
\hline Sample & $\begin{array}{c}\text { Coal/Solvent } \\
\text { Ratio }\end{array}$ & $\begin{array}{c}\text { Temperature } \\
\left({ }^{\circ} \mathrm{C}\right)\end{array}$ & $\begin{array}{l}\text { Pressure } \\
\quad(p s i)\end{array}$ & Outcome \\
\hline \multirow{5}{*}{ A- $053000-1$} & \multirow{5}{*}{$1: 2$} & \multirow{5}{*}{200} & 10 & no filtrate \\
\hline & & & 15 & no filtrate \\
\hline & & & 30 & no filtrate \\
\hline & & & 50 & no filtrate \\
\hline & & & 100 & no filtrate \\
\hline \multirow{5}{*}{ “ } & \multirow{5}{*}{ “ } & \multirow{5}{*}{250} & 10 & no filtrate \\
\hline & & & 15 & no filtrate \\
\hline & & & 30 & no filtrate \\
\hline & & & 50 & no filtrate \\
\hline & & & 100 & no filtrate \\
\hline \multirow{5}{*}{ “ } & \multirow{5}{*}{ “ } & \multirow{5}{*}{300} & 10 & no filtrate \\
\hline & & & 15 & no filtrate \\
\hline & & & 30 & no filtrate \\
\hline & & & 50 & no filtrate \\
\hline & & & 100 & no filtrate \\
\hline \multirow{5}{*}{ “ } & \multirow{5}{*}{ “ } & \multirow{5}{*}{320} & 10 & no filtrate \\
\hline & & & 15 & no filtrate \\
\hline & & & 30 & no filtrate \\
\hline & & & 50 & no filtrate \\
\hline & & & 100 & few drops \\
\hline \multirow{5}{*}{ “ } & \multirow{5}{*}{ “ } & \multirow{5}{*}{350} & 10 & no filtrate \\
\hline & & & 15 & no filtrate \\
\hline & & & 30 & few drops \\
\hline & & & 50 & few drops \\
\hline & & & 100 & few drops \\
\hline
\end{tabular}


Table 8 - Qualitative filtration results for Western Kentucky coal and anthracene oil extraction mixtures, 1:3 and 1:4 (coal to solvent ratios) heated at $350{ }^{\circ} \mathrm{C}$ for 60 minutes.

\begin{tabular}{|c|c|c|c|c|}
\hline Sample & $\begin{array}{c}\text { Coal/Solvent } \\
\text { Ratio }\end{array}$ & $\begin{array}{c}\text { Temperature } \\
\left({ }^{\circ} \mathrm{C}\right)\end{array}$ & $\begin{array}{l}\text { Pressure } \\
\text { (psi) }\end{array}$ & Outcome \\
\hline \multirow{5}{*}{ A-061200-1 } & \multirow{5}{*}{$1: 3$} & \multirow{5}{*}{300} & 10 & few drops \\
\hline & & & 15 & few drops \\
\hline & & & 30 & constant drip \\
\hline & & & 50 & constant drip \\
\hline & & & 100 & constant drip \\
\hline \multirow{5}{*}{ “ } & \multirow{5}{*}{ “ } & \multirow{5}{*}{320} & 10 & constant drip \\
\hline & & & 15 & constant drip \\
\hline & & & 30 & constant drip \\
\hline & & & 50 & constant drip \\
\hline & & & 100 & constant drip \\
\hline \multirow{5}{*}{ A- $-060500-1$} & \multirow{5}{*}{$1: 4$} & \multirow{5}{*}{300} & 10 & slow filtration \\
\hline & & & 15 & rapid filtration \\
\hline & & & 30 & rapid filtration \\
\hline & & & 50 & rapid filtration \\
\hline & & & 100 & rapid filtration \\
\hline
\end{tabular}




\section{Evaluation of materials produced from co-pyrolysis of coal and MSW by HTI.}

As outlined in the amended contract objective, CAER and CONSOL Inc would evaluate heavy and light liquids respectively produced from co-pyrolysis experiments conducted by HTI.

HTI performed a series of scoping experiments and then 4 co-pyrolysis experiments using coal and simulated municipal solid waste (MSW). Data for the 4 co-pyrolysis experiments provided by HTI to CAER are summarized below in Tables 9,10 and 11 .

Using the above data CAER has made some yield and conversion calculations which are summarized in Table 12. The liquid product yield is calculated as the percentage of liquid materials produced from total mass of the reactor charge. The yield data includes water, but not gases. The percent conversion is calculated by the difference in mass of reactor charge and the char remaining in the reactor after pyrolysis.

Table 9 - Operating conditions, HTI's co-pyrolysis testing with Unit 270.

\begin{tabular}{|l|c|c|c|c|}
\hline Test Number & $\mathbf{2 7 0 - 1}$ & $\mathbf{2 7 0 - 2}$ & $\mathbf{2 7 0 - 3}$ & $\mathbf{2 7 0 - 4}$ \\
\hline Cold Gas Flowrate, scf/hr & 18.0 & 19.6 & 19.9 & 21.1 \\
\hline Sandbath Temperature Before Reactor Inserted, F & 1030 & 1030 & 1040 & 1050 \\
\hline Reactor Internal Temperature, F & 980 & 970 & 1020 & 1020 \\
\hline Hot Gas Flow in the Reactor, scf/hr & 49.8 & 53.8 & 56.6 & 59.9 \\
\hline Hot Gas Flow in the Reactor, cm/sec & 12.7 & 13.7 & 14.4 & 15.2 \\
\hline Time, min & 180 & 90 & 90 & 80 \\
\hline Time to Reach 900F, min & 22 & 19 & 41 & 25 \\
\hline
\end{tabular}


Table 10 - Summary of HTI's co-pyrolysis testing with Unit 270.

\begin{tabular}{|c|c|c|c|c|}
\hline Test Number & 270-01 & 270-02 & 270-03 & 270-04 \\
\hline Heat Exchanger & $\begin{array}{l}\text { Shell/Tube } \\
\text { Horizontal }\end{array}$ & $\begin{array}{c}\text { Shell/Tube } \\
\text { Vertical }\end{array}$ & $\begin{array}{c}\text { Coil in } \\
\text { Tank }\end{array}$ & $\begin{array}{c}\text { Coil in } \\
\text { Tank }\end{array}$ \\
\hline Cold Trap & NO & ICE & ICE & DRY ICE \\
\hline Number of Gas Samples & 0 & 1 & 3 & 3 \\
\hline Coal Screened to +100 mesh & NO & NO & YES & YES \\
\hline \multicolumn{5}{|l|}{ Reactor Charge } \\
\hline \multicolumn{5}{|l|}{ Black Thunder Coal 18-40 Mesh } \\
\hline HTI-7085 West Kentucky Coal <60 Mesh & 499.0 & 203.1 & 243.0 & \\
\hline HTI-7091 Med S Pittsburgh Coal <60 Mesh & & & & 226.6 \\
\hline Flat Cardboard 1/2" squares & & 40.6 & 48.6 & 45.3 \\
\hline Sawdust no chips & & 40.6 & 48.6 & 45.3 \\
\hline High Density Polyethylene pellets & & 9.4 & 11.2 & 10.5 \\
\hline Polypropylene pellets & & 9.4 & 11.2 & 10.5 \\
\hline Polystyrene pellets & & 9.4 & 11.2 & 10.5 \\
\hline TOTAL & 499 & 312 & 374 & 349 \\
\hline \multicolumn{5}{|l|}{ Product } \\
\hline $\mathrm{H} 2 \mathrm{O}$ in Receiver, gms & & 31 & & \\
\hline Oil in Receiver, gms & & 6 & 1.6 & \\
\hline Light Yellow Oil from the cold trap, gms & & 2.5 & & \\
\hline Tar/Sludge mixed with Water from the cold trap, gms & & & 25.8 & 34.9 \\
\hline Tar from THF washing/roto-evap & & 7.2 & 20.3 & 30.4 \\
\hline Oil from THF washing/roto-evap & 21.6 & & & \\
\hline Dry Powder from THF washing/roto-evap & 13.0 & 6.1 & & \\
\hline Char remaining in the reactor, gms & 301 & 189 & 191 & 187 \\
\hline Gas Recovery & & 12.9 & 28.4 & 34.8 \\
\hline TOTAL gms, no gases & 335.6 & 241.8 & 238.7 & 252.3 \\
\hline TOTAL gms, with gases & & 254.7 & 267.1 & 287.1 \\
\hline Material Recovery W\%, no gases & 67.3 & 77.4 & 63.8 & 72.4 \\
\hline Material Recovery W\%, with gases & & 81.5 & 71.4 & 82.3 \\
\hline
\end{tabular}


Table 11 - Summary of HTI's co-pyrolysis testing with Unit 270, comments.

\begin{tabular}{|c|l|}
\hline Test Number & \multicolumn{1}{|c|}{ Comment } \\
\hline $\mathbf{2 7 0 - 1}$ & No Gas samples taken or product flow rate measured. \\
\hline $\mathbf{2 7 0 - 2}$ & $\begin{array}{l}\text { Plugged off 10 minutes into the test. } \\
\text { Dry powder recovered is from fine coal dust carryover into the downstream equipment. }\end{array}$ \\
\hline $\mathbf{2 7 0 - 3}$ & $\begin{array}{l}\text { The water missing from 270-03 was probably stripped from the cold trap by the gas. } \\
\text { Cold trap contains mostly tar/sludge with a thin film of dirty water. }\end{array}$ \\
\hline $\mathbf{2 7 0 - 4}$ & Cold trap contains approximately 2/3 tar/sludge and 1/3 dirty water. \\
\hline
\end{tabular}

Table 12 - Yield and conversion data calculated by CAER.

\begin{tabular}{|c|c|c|}
\hline $\begin{array}{c}\text { Experiment } \\
\text { No. }\end{array}$ & $\begin{array}{c}\text { Liquid Yield } \\
(\mathbf{\%})\end{array}$ & $\begin{array}{c}\text { Conversion } \\
(\mathbf{\%})\end{array}$ \\
\hline $270-01$ & 8.6 & 39.7 \\
\hline $270-02$ & 17.1 & 39.5 \\
\hline $270-03$ & 14.6 & 48.9 \\
\hline $270-04$ & 20.0 & 46.4 \\
\hline
\end{tabular}

Given the very small amount of material produced in these experiments, samples received have been split into two; one half of the material will be forwarded to CONSOL, Inc and the other half kept by CAER. The amount of liquid material produced is insufficient for any detailed evaluation by CAER. At best some simple analyses will be attempted.

The earlier scoping experiments and the 4 pyrolysis experiments conducted by HTI either did not produce any usable material or an insufficient quantity for complete evaluation. Furthermore, HTI have exhausted their allocated budget for this project and therefore are not in a position to conduct any further experimental work. Taking these factors into account, a series of copyrolysis experiments will be conducted at CAER by CAER staff, using CAER equipment. These experiments will be conducted at zero cost to the project and plan to provide suitable quantities of material for further evaluation and to fulfill the requirements of the DOE contract, DOE/PC/9140. 


\section{Progress Meeting}

A progress meeting attended by the following personnel was held at HTI on 10 May 2000.
- HTI,
Dr. Al Comolli
- HTI,
Mr. Robert Stalzer
- HTI,
Dr. Peizheng Zhou
- CAER,
Dr. Adam Berkovich
- CAER,
Dr. Burtron Davis
- CAER,
Dr. Chris Lafferty
- CONSOL Inc,
Dr. Jeffrey Withum
- DOE NETL,
Dr. Michael Nowak
- LDP Associates, Mr. Michael Peluso

The major points from the meeting are summarized as follows.

CAER:

- CAER presented a brief overview of the revised project work plan. As well, CAER advised that Dr. Chris Lafferty would be leaving CAER at the end May 2000.

- A summary of progress to date was presented. This included: extraction optimization experiments; controlling pitch softening point; fiber fabrication; fiber stabilization; fiber carbonization; fiber properties; mass balance data.

- CAER also advised of work in progress that included: solvent recycling; further fiber fabrication; refinement of mass balances; pitch characterization. As well up-to-date extraction data would be forwarded to LDP Associates for evaluation.

CONSOL Inc:

- After recent restructuring at CONSOL Inc, Dr. Jeffrey Withum had been appointed CONSOL's new project manager for the Advanced Concepts project. Furthermore, despite the recent changes at CONSOL, CONSOL was still committed to completion of the project.

- Dr. Withum advised that he would require some time to formulate a work plan and that he would keep the group advised of progress.

- CONSOL also provided some analytical results for distillation condensates provided by CAER

HTI:

- HTI advised that 1 run with recently constructed Pyrolysis Unit 270 had been completed. The first run using only Western Kentucky Coal produced $22 \mathrm{~g}$ of liquid material equal to $4.3 \%$ weight of the charge. Mass balance was closed at only $67.3 \%$. Some suggestions were made for improving the mass balance. These including installation of cold traps on 
the outlet of the rig or activated carbon filters to trap liquid vapors flowing out of the reactor more effectively.

- Three more runs with coal and MSW were planned, and the liquid materials would be forwarded to CAER and CONSOL for further evaluation.

- HTI advised that the planned 4 runs would probably exhaust their budget for the project. And it would be unlikely that further experimental work would be performed after the $4^{\text {th }}$ run.

\section{LDP Associates:}

- Technoeconomic analyses continue, with data provided by HTI and CAER.

- A speculative, elementally based, material balance was prepared and presented for both extraction and pyrolysis processes. Product revenues were calculated based on the assumed yields and current market prices. Pitch value was a critical factor for the extraction process. Production of oxygenated liquids was a key factor in determining product revenue in both cases. 
2. SECTION TWO

LDP ASSOCIATES 


\section{LDP ASSOCIATES}

Michael Peluso, Proprietor

32 Albert E. Bonacci Dr.

609-586-2301

Hamilton Square, N.J. 08690

Dr. Adam Berkovich

August 11, 2000

Center for Applied Energy Research

2540 Research Park Drive

Lexington, Kentucky 40511-8410

Dear Adam,

Subject: QUARTERLY PROGRESS REPORT FOR APRIL-JUNE 2000

During the quarter ending June 30, 2000 the following subcontract services (UKRF-4-25582-92-

75) were performed in support of the DOE Advanced Concepts Program (DE-AC22-

91PC91040):

\section{CAER EXTRACTION DATA}

The latest extraction unit configuration was discussed with CAER. A review of the latest run data was begun.

\section{HTI PYROLYSIS DATA}

The review of HTI's modifications to their pyrolysis unit for improving liquids production was completed. The results of the first run with the new unit were discussed with HTI and CAER. A review was begun of the final pyrolysis unit data received from HTI. Despite major

modifications to the liquid product recovery system, a significant amount (approx. 20\%) of the unit feed could not be accounted for. Comments were discussed with CAER.

\section{CONSOL WORK PLAN}

Various aspects of their work plan were discussed with CONSOL.

\section{IDENTIFICATION OF TARGETED PRODUCTS}

An update of the Hierarchy of Product Values was prepared based on April 2000 prices (see Table 1).

A brief investigation of the current carbon fiber market size and a petroleum-based fiber production technique were made. The findings of this investigation were discussed with CAER.

\section{TECHNOECONOMIC ANALYSIS}

A speculative, elementally balanced, material balance was prepared for both the extraction and pyrolysis processes (see Tables $2 \& 3$ ). Product revenues were calculated based on the assumed yields and current market prices. Pitch value is a critical factor for the extraction process. The yield of oxygenated liquids is a key factor in determining product revenue in both cases. These product revenues compare favorably with the \$125/Ton MF revenue determined for the Base Case (Direct Liquefaction case based on Wilsonville Run\#263J). 
Moreover, the capital and operating costs of the extraction and pyrolysis processes are expected to be only a fraction of the corresponding Base Case costs. If, for example, the production costs of the extraction and pyrolysis processes were half those of the Base Case, then the projected revenue-to cost ratio of these two processes would be 60 to $75 \%$ higher than the Base Case. The extent to which this projected economic advantage can be realized depends on the degree to which future experimental results confirm the estimated yields and values used in the analysis.

The speculative material balances for the extraction and pyrolysis processes indicated that the yield of light oxygenated liquids (LOLS) was a key factor in determining product revenue. In an effort to better estimate the yield of LOLS, reports from previous coal liquids characterization work by the Bartlesville Energy Research Center (BERC) are being obtained. A review of the only report received to date (COED pyrolysis oil from W. Kentucky coal) was begun.

\section{ALC-1 \& 2 CLOSEOUT REPORT}

CAER confirmed the need for LDP Associates to prepare a draft of the above report for comments by team members. A review of the above runs was begun as background for preparing the report. A review of the latest version of the Advanced Concepts design case was also made.

\section{MISCELLANEOUS}

A project review meeting at HTI on May 10th was attended. A meeting with CAER in Lexington was held on May 25th.

\section{SHORT TERM WORK PLAN}

- Review BERC coal liquid characterization reports; Re: Estimated LOLS yields.

- Continue to assess the economics of the extraction and pyrolysis processes.

- Begin preparation of the ALC-1\&2 closeout report.

- Continue to analysis \& evaluation CAER extraction run data.

- Complete review of HTI pyrolysis run data.

cc: B. Davis@ CAER

Very truly yours,

Michael Peluso

LDP Associates

J.Withum@CONSOL

P.Zhou/R.Stalzer@HTI 
Table 1 - CAER Advanced Concepts: Hierarchy of Product Values

\begin{tabular}{|l|c|c|l|}
\hline \multicolumn{1}{|c|}{ PRODUCT } & PRICE, Cents/lb. & & \multicolumn{1}{|c|}{ COMMENTS } \\
\hline High Sulfur Petroleum Coke & 0.0 & E & At Refinery \\
\hline PRB Subbituminous Coal & 0.24 & & Aug.'99 @ Mine (Coal Age) \\
\hline Sulfuric Acid & 2.5 & & Apr.'00 CMR \\
\hline Metallurgical Coke & 6.0 & & Dec.'99 New Steel \\
\hline Natural Gas (Pipeline Receipt) & 6.7 & A & $\$ 2.81 /$ MMBtu Spot Apr.'00 O\&GJ \\
\hline Calcined Low Sulfur Petroleum Coke & 7.0 & E & Used in Anodes for Aluminum \\
\hline Crude Oil (W.Texas Intermediate) & 8.7 & A & $\$ 25 /$ bbl, Apr.'00 (O\&GJ) \\
\hline Low Sulfur FCC Decant Oil & 8.5 & E & For Prem. C Prod's; Crude + \$6/bbl. \\
\hline Creosote Oil & 10.2 & & $\$ 0.925 /$ gal., Apr'00 CMR \\
\hline Gasoline @ \$25/bbl Crude Oil Price & 12.3 & E & Sales to Resellers; Crude + \$8/bbl. \\
\hline Benzene & 17.7 & & $\$ 1.30 /$ gal., Apr.'00 CMR \\
\hline Toluene & 14.0 & & $\$ 1.01 / g a l .$, Apr.'00 CMR \\
\hline Xylenes, Mixed & 14.2 & & $\$ 1.03 /$ gal., Apr.'00 CMR \\
\hline p-Xylene & 18.3 & & Apr.'00 CMR \\
\hline Coal Tar Pitch & 15.8 & & Alum. Anode Binder; Sept.'99 CMR \\
\hline o-Xylene & 20.0 & & Apr.'00 CMR \\
\hline Crude Napthhalene (78 deg.C m.p.) & 26.0 & & Apr.'00 CMR \\
\hline Premium Needle Coke (Calcined) & 30.0 & E & \\
\hline Phenol & 38.0 & & Apr.'00 CMR \\
\hline Fully Refined Paraffin Wax & 37.0 & & Apr.'00 CMR \\
\hline Crude Napthhalene (80 deg.C m.p.) & 39.0 & & Apr.'00 CMR \\
\hline Mixed Cresylics (>25\% m+p cresol) & 55.0 & & From Coal Tar; Apr.'00 CMR \\
\hline o-Cresol (99\%) & 73.5 & & Apr.'00 CMR \\
\hline m,p-Cresol (99\%) & 90.0 & & Apr.'00 CMR \\
\hline Granular Activated Carbon & 92.0 & & Apr.'98 CMR \\
\hline m-Cresol (95-98\%) & 125.0 & & Apr.'00 CMR \\
\hline p-Cresol (98\%) & 182.0 & & Apr.'00 CMR \\
\hline Catechol [C6H4(OH)2] & 210.0 & & Apr.'00 CMR \\
\hline Refined Pyridine (1 Deg,C b.r.) & 379.0 & & Apr.'00 CMR \\
\hline Carbon Fibres (General Purpose) & 1000.0 & E $\$ 5 /$ lb. Target Price \\
\hline Activated Carbon Fibres & 1600.0 & & June '99 CAER \\
\hline Carbon Fibres (Aerospace Appl's) & 10000.0 & & May '97 CMR \\
\hline Platinum & 703000.0 & & $\$ 482 /$ troy oz., Apr.'00 New Steel \\
\hline Notes: & & & \\
\hline A= Average & & & \\
\hline E= Estimated & & & \\
\hline CMR= Chemical Market Reporter & & & \\
\hline OG\&J= Oil \& Gas Journal & & & \\
\hline
\end{tabular}


Table 2 - CAER Advanced Concepts: Material Balances and Product Revenue

\begin{tabular}{|c|c|c|c|c|c|c|c|}
\hline & \multicolumn{5}{|c|}{ ESTIMATED SOLVENT EXTRACTION CASE WITH BLACK THUNDER COAL } & \multirow[b]{2}{*}{ S } & \multirow[b]{2}{*}{ Total } \\
\hline & Yield, lb/100lb MF & C & $\mathrm{H}$ & $\mathrm{O}$ & $\mathrm{N}$ & & \\
\hline Phenol + Cresylics & 4.00 & 77.00 & 6.57 & 16.43 & 0.00 & 0.00 & 100.00 \\
\hline Other Distillates & 4.00 & 89.00 & 7.50 & 2.00 & 1.00 & 0.50 & 100.00 \\
\hline Wax & 2.00 & 85.00 & 15.00 & 0.00 & 0.00 & 0.00 & 100.00 \\
\hline Pitch & 14.40 & 90.40 & 5.50 & 2.15 & 1.30 & 0.65 & 100.00 \\
\hline HC Gas & 1.00 & 80.00 & 20.00 & 0.00 & 0.00 & 0.00 & 100.00 \\
\hline $\mathrm{CO} 2$ & 5.00 & 27.29 & 0.00 & 72.71 & 0.00 & 0.00 & 100.00 \\
\hline Water & 5.00 & 0.00 & 11.19 & 88.81 & 0.00 & 0.00 & 100.00 \\
\hline \multirow[t]{2}{*}{ Ash Free Solids } & 59.00 & 79.28 & 3.87 & 14.88 & 1.31 & 0.66 & 100.00 \\
\hline & 94.40 & 70.30 & 4.70 & 17.90 & 1.00 & 0.50 & 94.40 \\
\hline \multirow[t]{3}{*}{ MAF Coal } & 94.40 & 70.30 & 4.70 & 17.90 & 1.00 & 0.50 & 94.40 \\
\hline & Out - In & 0.00 & 0.00 & 0.00 & 0.00 & 0.00 & 0.00 \\
\hline & & & & & & & REVENUE \\
\hline \multirow[t]{2}{*}{ HHV, Ash Free Solids } & 12804 & & & PRODUCT & & Cents/lb. & $\$ /$ Ton MF \\
\hline & & & & \multicolumn{2}{|c|}{ Phenol + Cresylics } & 40.00 & 32.00 \\
\hline Ash & 5.60 & & & \multicolumn{2}{|l|}{ Other Distillates } & 7.00 & 5.60 \\
\hline \multirow[t]{2}{*}{ Total Solids } & 64.60 & & & Wax & & 37.00 & 14.80 \\
\hline & & & & Pitch & & 16.00 & 46.08 \\
\hline \multirow[t]{2}{*}{ HHV Solids } & 11694 & & & Solids & & 1.00 & 12.92 \\
\hline & & & & & & Total & 111.40 \\
\hline
\end{tabular}


Table 3 - CAER Advanced Concepts: Material Balances and Product Revenue

\begin{tabular}{|c|c|c|c|c|c|c|c|}
\hline & \multicolumn{4}{|c|}{ ESTIMATED PYROLYSIS CASE WITH BLACK THUNDER COAL } & \multirow[b]{2}{*}{$\mathrm{N}$} & \multirow[b]{2}{*}{$\mathrm{S}$} & \multirow[b]{2}{*}{ Total } \\
\hline & Yield, lb/100lb MF & C & $\mathrm{H}$ & $\mathrm{O}$ & & & \\
\hline Phenol + Cresylics & 9.00 & 77.00 & 6.57 & 16.43 & 0.00 & 0.00 & 100.00 \\
\hline Other Distillates & 9.00 & 89.00 & 7.50 & 2.00 & 1.00 & 0.50 & 100.00 \\
\hline Wax & 0.00 & 85.00 & 15.00 & 0.00 & 0.00 & 0.00 & 100.00 \\
\hline Pitch & 0.00 & 90.40 & 5.50 & 2.12 & 1.33 & 0.65 & 100.00 \\
\hline HC Gas & 1.00 & 80.00 & 20.00 & 0.00 & 0.00 & 0.00 & 100.00 \\
\hline $\mathrm{CO} 2$ & 0.00 & 27.29 & 0.00 & 72.71 & 0.00 & 0.00 & 100.00 \\
\hline Water & 7.00 & 0.00 & 11.19 & 88.81 & 0.00 & 0.00 & 100.00 \\
\hline \multirow[t]{2}{*}{ Ash Free Solids } & 68.40 & 79.77 & 3.58 & 14.66 & 1.33 & 0.66 & 100.00 \\
\hline & 94.40 & 70.30 & 4.70 & 17.90 & 1.00 & 0.50 & 94.40 \\
\hline \multirow[t]{3}{*}{ MAF Coal } & 94.40 & 70.30 & 4.70 & 17.90 & 1.00 & 0.50 & 94.40 \\
\hline & Out - In & 0.00 & 0.00 & 0.00 & 0.00 & 0.00 & 0.00 \\
\hline & & & & & & & REVENUE \\
\hline \multirow[t]{2}{*}{ HHV, Ash Free Solids } & 12712 & & & PRODUCT & & Cents/lb. & \$/Ton MF \\
\hline & & & & \multicolumn{2}{|c|}{ Phenol + Cresylics } & 40.00 & 72.00 \\
\hline Ash & 5.60 & & & \multicolumn{2}{|l|}{ Other Distillates } & 7.00 & 12.60 \\
\hline \multirow[t]{2}{*}{ Total Solids } & 74.00 & & & Wax & & 37.00 & 0.00 \\
\hline & & & & Pitch & & 16.00 & 0.00 \\
\hline \multirow[t]{2}{*}{ HHV Solids } & 11750 & & & Solids & & 1.00 & 14.80 \\
\hline & & & & & & Total & 99.40 \\
\hline
\end{tabular}

